\title{
LONG-TERM FOLLOW-UP OF IMPLANTS WITH REDUCED
}

\section{LENGTH}

\author{
Stefan Peev ${ }^{1}$, Elitsa Sabeva ${ }^{1}$, Angela Gusiyska ${ }^{2}$, Tihomir Georgiev ${ }^{3}$, Tsvetan Tonchev ${ }^{3}$ \\ ${ }^{1}$ Department of Periodontology and Dental Implantology, Faculty of Dental Medicine, \\ Medical University of Varna \\ ${ }^{2}$ Department of Conservative dentistry, Faculty of Dental Medicine, \\ Medical University - Sofia \\ ${ }^{3}$ Department of Oral and Maxillofacial Surgery and Special Imaging Diagnostic, \\ Faculty of Dental Medicine, Medical University of Varna
}

\begin{abstract}
INTRODUCTION: The aim of this study was to assess the reduced length implants as an alternative of conventional length implants in combination with bone augmentation. The following criteria were observed: survival rate, marginal bone loss, bleeding on probing.

MATERIAL AND METHODS: This study included 186 Straumann Standard Plus implants with dimensions: length of $6 \mathrm{~mm}$ and diameter of $4.8 \mathrm{~mm}$. The implants were loaded with non-removable crowns or bridges at least 10 weeks after the implant placement. Depending on the type of the prosthetic option the distribution of the implants was as follows: 83 implants were co-abutments to one more implant with conventional length $(8-14 \mathrm{~mm})$; 67 implants were co-abutments to more than one implant with conventional length, 33 implants were loaded with single crowns.

RESULTS: The mean period of observation was 5.59 years. The mean marginal bone resorption was $0,224 \mathrm{~mm}$. In $12.4 \%$ from the cases was registered BOP (bleeding on probing). A correlation was found between the BOP and mean marginal bone resorption. No correlation was found between the values of marginal bone resorption and the type of the prosthetics. The survival rate of the implants in the observation period was $99.5 \%$.

CONCLUSION: Treatment by short implants is a reliable alternative to implants with conventional length with combination of bone grafting procedures. It is less invasive, cost effective and consumes less treatment time.
\end{abstract}

Keywords: implants with reduced length, short implants

Address for correspondence:

Stefan Peev

Department of Periodontology and Dental Implantology

Faculty of Dental Medicine

Medical University of Varna

84 Tzar Osvoboditel Blvd.

9000 Varna, Bulgaria

e-mail: stefan.peev@mail.bg

Received: December 3, 2015

Accepted: December 14, 2015

\section{INTRODUCTION}

The aim of many studies was to evaluate the treatment with short implants as a reliable and less invasive alternative to placement of conventional length implants in combination with bone augmentation procedures.

Renouard and Nisand (1) defined as ,short' implants those with intraosseal length of less than 8 mm. Many authors described both methods as al-

Scripta Scientifica Medicinae Dentalis, vol. 1, №2, 2015, pp. 49-52 
most equally reliable, predictable and with almost the same success rate $(2,3)$. Thoma et al. (4) compared the survival rate of 70 implants placed in combination with sinus lift with a lateral access and 67 short implants placed in the distal area of the upper jaw, without bone augmentation. They monitored them for 18 months. The authors reported 100\% survival rate for both groups. Similar results were reported by other authors: Gulje et al. (3), Pistilli and et al. $(5,6)$. The conclusion of many studies was that there was no significant difference between the survival rate of short implants with modification of the surface topography and conventional length implants $(2,7,8)$. Hentschel et al. (9), in a study which included 649 implants, concluded that the implant length had no significant influence on the survival rate for a period of two years.

In a system literature review Thoma et al. (10) implants with dimensions: length of $6 \mathrm{~mm}$ and diameter of $4.8 \mathrm{~mm}$. The distribution of the implants according to area is shown in Fig. 1. After elevation of the muco-periosteal flap using one horizontal incision along the alveolar ridge and one or two paramedian vertical incisions, the osteotomy for the implant placement was performed in the following clinical protocol:

1. The position of the osteotomy was marked with $1.4 \mathrm{~mm}$ round bur.

2. The mark was expanded with $2.3 \mathrm{~mm}$ round bur.

3. Pilot osteotomy was done with a $2.2 \mathrm{~mm}$ pilot drill to the appropriate depth at a maximum speed of $800 \mathrm{rpm}$.

4. The osteotomy was enlarged to the desired diameter consecutively with increasing diameter twist drills $-2.8 \mathrm{~mm}, 3.5 \mathrm{~mm}$ and $4.2 \mathrm{~mm}$.

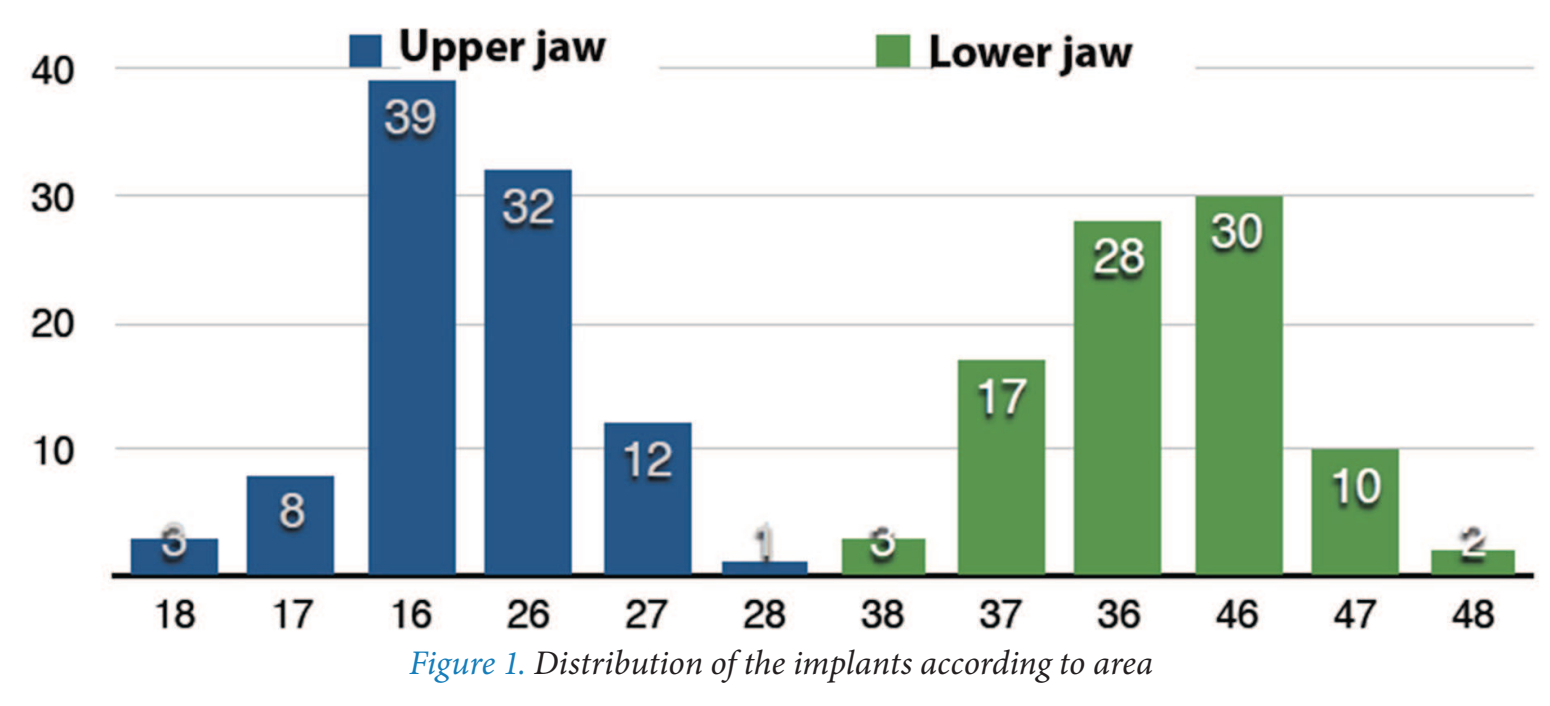

concluded that short implants placed in the distal areas of non augmented maxilla had similar survival rates compared to implants placed in combination with sinus lift. In connection with the typical for the augmentation of the maxillary sinus complications, the increased cost and extended treatment time, short implants were the preferred alternative.

\section{MATERIAL AND METHODS}

The success rate of implants with reduced length was observed for a period of one to six years. This study included 186 Straumann Standard Plus
The osteotomy was performed with continuous cooling with sterile saline solution. The cased were done under local anesthesia using a $4 \%$ articaine solution with adrenaline 1/100 000 (Septanest - Septodont, France).

The flap was repositioned and sutured using 5/0 monofilament polyamide thread (Dafilon, B. BraunMelsungen, Germany) with single interrupted sutures. Second stage surgery was performed 3 months after the implant placement. The implants were loaded with single crowns or bridges at least 10 weeks af- 
Stefan Peev, Elitsa Sabeva, Angela Gusiyska et al.

ter the implant placement. Depending on the type of the prosthetic option the distribution of the implants was as follows: 83 implants were co-abutments to one more implant with conventional length $(8-14 \mathrm{~mm})$; 67 implants were co-abutments to more than one implant with conventional length, 33 implants were loaded with single crowns. During the control visit we registered: absence or presence of exudation, $\mathrm{BOP}$ (bleeding on probing) and marginal bone resorption visible on radiography, survival rate. Probing was performed with periodontal probe UNC-15. The level of the bone registered on radiography. The implant length was used as a reference. The appearance of marginal bone resorbtion was measured from the border between the treated (modified surface topography) and polished part of the implant.

\section{RESULTS}

The cases were observed from 5 to 6 years, with a mean period of observation of 5.59 years. The mean age of the patients was 51.43 years. The survival rate of the implants for the period of the observation was 99.5\%.

The mean marginal bone loss was $0.224 \mathrm{~mm}$. BOP was registered in $12.4 \%$ of the cases. A correlation was found between $\mathrm{BOP}$ and mean marginal bone loss. In the cases without BOP, the mean marginal resorption was 0.13 , and in the cases where there we registered BOP the mean marginal bone loss was 0.89 . No correlation was found between the values of marginal bone resorption and the type of prosthetic option.

\section{DISCUSSION}

The survival rate of the implants with reduced length according to our study was $99.5 \%$. Srinivasan et al. (11), Thoma et al. (4), Gulje and et al. (3) and Pistilli et al. $(5,6)$ reported similar results. The mean marginal bone loss was 0.224 . The implants with size $4.8 / 6 \mathrm{~mm}$ with SLA modification of the surface topography are reliable alternative to conventional length implant placement in a combination with bone augmentation in both - upper and lower jaw as they show similar survival rate and marginal bone loss. The short implants are not recommended in cases with increased esthetic risk where the restoration of bone volume and soft tissue esthetic is necessary.

\section{CONCLUSION}

Treatment by short implants is a reliable alternative to implants with conventional length with combination of bone grafting procedures. It is less invasive, cost effective and consumes less treatment time with less perioperative complications.

\section{REFERENCES}

1. Renouard F, Nisand D. Impact of implant length and diameter $r$ on survival rates. Clin Oral Imp Res. 2006;17(Suppl. 2):35-51.

2. Esposito M, Cannizzaro G, Soardi E, Pistilli R, Piattelli M, Corvino V, Felice P. Posterior atrophic jaws rehabilitated with prostheses supported by 6 $\mathrm{mm}$-long, $4 \mathrm{~mm}$-wide implants or by longer implants in augmented bone. Preliminary results from a pilot randomised controlled trial. European Journal of Oral Implantology. 2012;5:19-33.

3. Gulje F, Abrahamsson I, Chen S, Stanford C, Zadeh $\mathrm{H}$, Palmer R. Implants of $6 \mathrm{~mm}$ vs. $11 \mathrm{~mm}$ lengths in the posterior maxilla and mandible: a 1-year multi center randomized controlled trial. Clinical Oral Implants Research. 2013;24:1325-31.

4. Thoma DS, Haas R, Tutak M, Garcia A, Schincaglia GP, Hammerle CHF. Randomized controlled multicenter study comparing short dental implants (6 $\mathrm{mm}$ ) versus longer dental

5. implants $(11-15 \mathrm{~mm})$ in combination with sinus floor elevation procedures. Part 1:demographics and patient-reported outcomes at 1 year of loading. Journal of Clinical Periodontology. 2015;42:72-80.

6. Pistilli R, Felice P, Cannizzaro G, Piatelli M, Corvino V, Barausse C, Buti J, Soardi E, Esposito M. Posterior atrophic jaws rehabilitated with prostheses supported by $6 \mathrm{~mm}$ long $4 \mathrm{~mm}$ wide implants or by longer implants in augmented bone. One-year post-loading results from a pilot randomized controlled trial. European Journal of Oral Implantology. 2013;6:359-72.

7. Pistilli R, Felice P, Piattelli M, Gessaroli M, Soardi E, Barausse C, Buti J, Corvino V. Posterior atrophic jaws rehabilitated with prostheses supported by $5 \mathrm{x}$ $5 \mathrm{~mm}$ implants with a novel nanostructured calcium-incorporated titanium surface or by longer implants in augmented bone. One-year results from a randomised controlled trial. European Journal of Oral Implantology. 2013;6:343-57.

8. Atieh MA, Zadeh H, Stanford CM, Cooper LF. Survival of short dental implants for treat-

Scripta Scientifica Medicinae Dentalis, vol. 1, №2, 2015, pp. 49-52 
Long-term follow-up of implants with reduced length

ment of posterior partial edentulism: a systematic review. Int J Oral Maxillofac Implants. 2012 Nov-Dec;27(6):1323-31.

9. Kotsovilis et al A systematic review and meta-analysis on the effect of implant length on the survival of rough-surface dental implants. J Periodontol. 2009 Nov;80(11):1700-18.

10. Hentschel A, Herrmann J, Glauche I, Vollmer A, Schlegel KA, Lutz R. Survival and patient satisfaction of short implants during the first two years of function: a retrospective cohort study with $694 \mathrm{im}$ plants in 416 patients. Clin Oral Implants Res. 2015 Jun 10. doi: 10.1111/clr.12626. [Epub ahead of print]

11. Thoma DS, Zeltner M, Husler J, Hammerle CHF, Jung RE. EAO Supplement Working Group 4 EAO CC 2015 Short implants versus sinus lifting with longer implants to restore the posterior maxilla: a systematic review. Clin Oral Implants Res. 2015 Sep;26 Suppl 11:154-69.

12. Srinivasan $M$, Vazquez L, Rieder $P$, Moraguez $O$, Bernard JP, Belser UC. Survival rates of short (6 $\mathrm{mm}$ ) micro-rough surface implants: a review of literature and meta-analysis. Clin Oral Implants Res. 2014 May;25(5):539-45. 